\title{
Bringing Research and Practice Together to Examine Student Voice: A commentary from BELMAS
}

The driving purpose of BELMAS, the British Educational Leadership, Management and Administration Society, is to provide a distinctive, independent and critical voice in the pursuit of quality education through effective leadership and management, and to bring together both academics and practitioners in this endeavour. Achieving this purpose involves an interconnected concern to analyse and probe the policy frameworks in education that constitute the context for education and the exercise of leadership and management.

The special issue in this volume of Management in Education exemplifies how BELMAS seeks to facilitate the sharing of research and ideas in pursuit of its driving purpose. Its theme of student voice enables a concentrated focus on the majority group making up membership of

school organisations - namely, students - and asks searching and critical questions concerning what a strong policy impetus (which favours listening to and involving students) means in practice. Insights are given, for example, into students' own views (how they resonate with research on constructing learning communities, how students view relationships and trust that underpin the experience of student voice, and so on) and into the different interpretations that are given to student voice, including the consequences of interpreting student voice as a means of delivering instrumental data sets. The articles also highlight implications and ideas for the practice of leadership and management. Integral to the work of BELMAS is a concern to encourage the identification of what practitioners may usefully gain from research, which will help them in their critical reflections on the future development of their professional and organisational policies and practices. If students are expert and insightful participants in the educational process, what are the kinds of approaches and strategies that will help institutions harness this for the good of students' learning? How can that learning be understood and assessed? In what ways is student voice narrowed and rendered one of many techniques deployed to make students better 'products' of an instrumentalised education system? These and other issues are raised by the contributors. They are issues of central concern to all those who play a part in the leadership and management of education at whatever level. This special issue demonstrates too the importance BELMAS attaches to practitioners and academic researchers working in partnership in the study of such issues. Practitioners are present in the special issue as individual authors reflecting on their experience and practice and as co-authors of research. One of the contributors, for example - a headteacher - concludes from his experience of being interviewed by students and his subsequent reflections that 'the real reason why student panels are regarded with suspicion [is that as] adults we find it difficult to admit that we do not have a monopoly when it comes to creativity and insight'. In various ways the contributions to this special issue illustrate how students should be understood as active participants in the ongoing leadership of education, whilst, at the same time, showing how students as a group, or some individuals or sections of the student population, may be marginalised or not well served by some of the strategies or practices that are labelled as student voice. For BELMAS, bringing together UK and international experience and helping to disseminate research that is both theoretically and practically informed are key processes in helping to advance practice. This special issue does both of these things. BELMAS is delighted to be able to provide a forum for the research and discussion. It is especially fitting that the special issue is part of BELMAS's 40th anniversary commemorations. It shows how the field of leadership and management embraces those who are at the centre of the learning 
process. On behalf of BELMAS, I congratulate all those who have contributed to writing for, and helped to bring to fruition, this special issue. 